\title{
Evaluating the Surveillance System for Spotted Fever in Brazil Using Machine-Learning Techniques
}

\begin{abstract}
Diego Montenegro Lopez ${ }^{1,2 \star}$, Flávio Luis de Mello ${ }^{3}$, Cristina Maria Giordano Dias ${ }^{4}$, Paula Almeida ${ }^{4}$, Milton Araújo ${ }^{4}$, Monica Avelar Magalhães ${ }^{5}$, Gilberto Salles Gazeta ${ }^{2 *}$ and Reginaldo Peçanha Brasil ${ }^{1}$
\end{abstract}

\begin{abstract}
'Laboratório de Doenças Parasitárias, Instituto Oswaldo Cruz (IOC)/Fiocruz, Rio de Janeiro, Brasil, ${ }^{2}$ Laboratório de Referência Nacional em Vetores das Riquetsioses, IOC/Fiocruz, Rio de Janeiro, Brasil, ${ }^{3}$ Laboratory of Machine Intelligence and Computation Models, Electronic and Computer Engineering Department, Federal University of Rio de Janeiro, Rio de Janeiro, Brazil, " ${ }^{4}$ Secretaria de Estado de Saúde do Rio de Janeiro - SES, Rio de Janeiro, Brasil, ${ }^{5}$ Instituto de Comunicação e Informação Científica e Tecnologia em Saúde - ICICT, Rio de Janeiro, Brasil
\end{abstract}

This work analyses the performance of the Brazilian spotted fever (SF) surveillance system in diagnosing and confirming suspected cases in the state of Rio de Janeiro (RJ), from 2007 to 2016 (July) using machine-learning techniques. Of the 890 cases reported to the Disease Notification Information System (SINAN), 11.7\% were confirmed as SF, 2.9\% as dengue, $1.6 \%$ as leptospirosis, and $0.7 \%$ as tick bite allergy, with the remainder being diagnosed as other categories (10.5\%) or unspecified (72.7\%). This study confirms the existence of obstacles in the diagnostic classification of suspected cases of SF by clinical signs and symptoms. Unlike man-capybara contact (1.7\% of cases), man-tick contact (71.2\%) represents an important risk indicator for SF. The analysis of decision trees highlights some clinical symptoms related to SF patient death or cure, such as: respiratory distress, convulsion, shock, petechiae, coma, icterus, and diarrhea. Moreover, cartographic techniques document patient transit between RJ and bordering states and within RJ itself. This work recommends some changes to SINAN that would provide a greater understanding of the dynamics of SF and serve as a model for other endemic areas in Brazil.

Keywords: public health, epidemiology, spotted fever, machine-learning, decision trees, probabilistic neural networks

\section{INTRODUCTION}

Rickettsial diseases are zoonoses caused by bacteria of the genus Rickettsia that are transmitted mainly by ticks to mammalian hosts and accidentally to humans. The infections produce an acute fever and systemic complications that can lead to patient death if proper treatment is not provided in time (1-3).

In Brazil, the main rickettsiosis is spotted fever (SF), and infections caused by Rickettsia rickettsii are considered the most serious. Moreover, other pathogenic Rickettsia (R. parkeri and Rickettsia Atlantic Forest strain) are also reported in the country, although these cases may or may not be confirmed $(4,5)$.

Spotted fever is a systemic disease with nonspecific signs and symptoms during its early stages. Throughout its course, it can be easily confused with other diseases, but a few patients develop rashes, which is the best clinical indicator $(1,3,5-7)$. High lethality seems to be associated with inaccurate clinical suspicion, which affects diagnosis and treatment opportunity $(3,5,6)$.

Given this scenario, it is essential to analyze the efficacy of the Sistema de Informação de Agravos de Notificação-SINAN (Disease Notification Information System) in capturing, managing, and 
confirming suspected human cases of SF, and for providing information for analysis of its morbidity profile, thus contributing to decision-making at the municipal, state, and federal levels in Brazil.

Evaluation of a surveillance system (SS), such as SINAN, should promote the best use of public health resources by ensuring that only important problems are under surveillance, and that the SS operates efficiently. Insofar as possible, the evaluation of a SS should include recommendations for improving quality and efficiency (e.g., eliminating unnecessary duplication; assessing information potential of the included variables). Above all, an evaluation should assess whether a system is serving a useful public health function and meeting its objectives (8).

Therefore, apart from the monitoring system evaluation model proposed by Klaucke et al. (8), it is important to use other tools to identify the strengths and weaknesses of SINAN so that preventive measures can be implemented and improvements can be made in its organization in order to capture, manage, diagnose, and treat in a timely manner suspected cases of SF, and facilitate a reversal in mortality rates of the disease.

The techniques of machine-learning (ML); promise to be useful tools for evaluating the accuracy of the SS for SF since they are better suited to dealing with a large number of variables and performing massive data analyses than a human agent. From this perspective, this paper employs ML techniques, such as data mining and probabilistic neural network analysis combined with geographical information, in order to better understand the SS of SF (SINAN) in the state of Rio de Janeiro.

\section{MATERIALS AND METHODS}

\section{Study Area}

The state of Rio de Janeiro is located in the eastern portion of Brazil's Southeast Region and occupies an area of $43,777.954 \mathrm{~km}^{2}$ divided into 92 municipalities (Figure 1). It is the fourth smallest state (by area) in Brazil, yet has the highest population density $\left(365.23\right.$ inhabitants $\left./ \mathrm{km}^{2}\right)$ with an estimated population of $16,636,000$ inhabitants and is the most urbanized state in the country, with $97 \%$ of the population living in cities (9).

\section{Epidemiological Data}

The data presented here was obtained from SINAN and provided by the Secretaria de Estado de Saúde do Rio de Janeiro-SES/

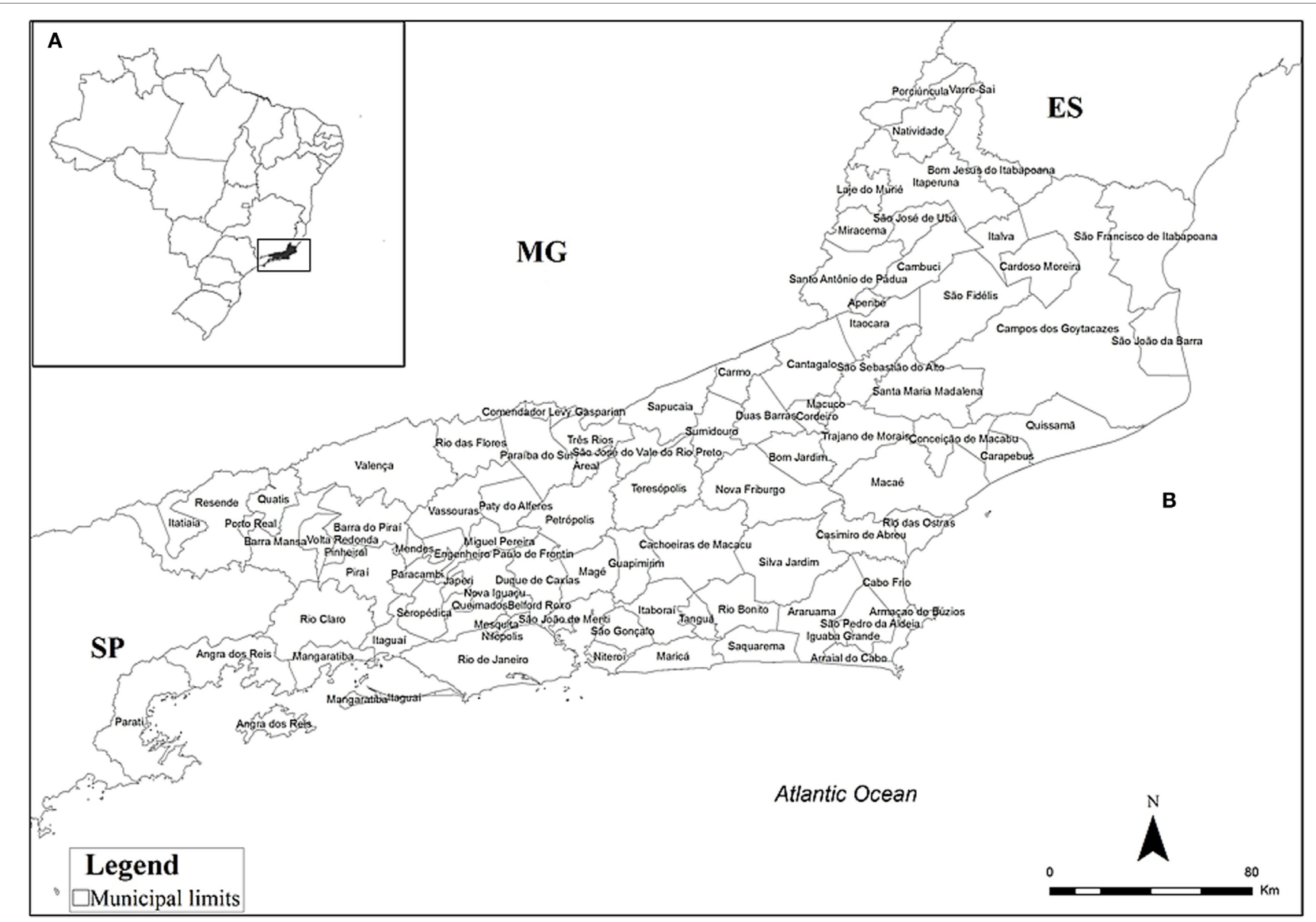

FIGURE 1 | Location of the state of Rio de Janeiro, Brazil, (A) and its municipalities (B). ES, Espírito Santo; MG, Minas Gerais; SP, São Paulo. 
RJ (State Secretary Health of Rio de Janeiro), and encompassed notifications of suspected cases of SF between 2007 and July 2016. These data were made available with the protection of the identity of the patients; therefore, information such as names or addresses cannot be displayed at any time to comply with national ethical regulations (10).

Although cases reported to SINAN were initially separated into those confirmed by laboratory tests (PCR or Serology) and/ or clinical and epidemiological nexus, unconfirmed cases and ignored cases, as reported in the corresponding epidemiological forms, all were included in the present study.

\section{Methods}

\section{Artificial Neural Networks}

Classification based on probabilistic neural networks (PNN) (11), which is a feed forward neural network, was the first ML technique implemented for identifying patterns concerning the classification of reported cases into different groups of pathologies. It is a nonparametric method for classifying observations in $n$ groups based on $p$ qualitative and/or quantitative input variables (12-14). It implements a statistical algorithm called Kernel discriminant analysis, whereby, processes are organized to feed forward a multiple network with four types of layers: input layer, pattern layer, addition layer, and output layer (15). Through a ML process, the PNN develops the mathematical ability to perform variable predictions and correctly classify observations within pre-established categories (12-14).

In addition to its advantages over other statistical tests $(11,15)$, PNN was selected for implementation because of the simple and fast way by which it can process large amounts of information $(11,14,15)$, the friendly way the network can be trained and its robustness to noise (14). The PNN has 31 input $(p)$ and 10 output $(g)$ variables. The sample space contains 528 of the 870 cases notified; the others were excluded because they did not contain information of provenance and/or lacked information regarding clinical signs. One hundred and two cases of patient records were selected for training, which contained information on area of residence (urban, peri-urban, and rural) and that confirmed 1 of the following 10 pathological categories (output) for composing the training set, as defined by SINAN: cellulitis, dengue, encephalitis, hepatitis A, leptospirosis, meningitis, other disease, SF, tick bite allergy, and virosis. The remaining 426 cases were used for testing the neural network. In this scenario, the input layer is composed of 22 clinical variables (fever, headache, abdominal pain, myalgia, nausea, rash, diarrhea, jaundice, hyperemia, hepatomegaly, petechiae, bleeding, lymphadenopathy, convulsion, necrosis, prostration, shock, coma, hemorrhage, respiratory distress, oliguria, other symptoms), 1 temporal variable (monthly reporting), 7 environmental variables [area of residence, contact with tick, capybara, dog/cat, cattle, horses, nature (forests, rivers, and waterfalls)]; and the variable hospitalization.

All variables except for the month of notification and area of residence were transformed into variables of ternary response ( $1=$ yes or presence, $-1=$ no or absence, and $0=$ no information) to provide values with scales easily comparable to each other. The PNN analyses were done by using the statistical package StatgraphicCenturium XVII (16).

\section{Knowledge Discovery}

In this work, we used another ML technique combined with data mining. Briefly, the goal was to automatically build a knowledge representation (17) by using algorithms that process combinatorial searches and discover correlations in large volumes of data. The algorithms used are associated with a technique called decision trees (18), such as: Best First Decision Tree, Decision Stump, Functional Tree, J48, Logistic Model Trees, Reduced-Error Pruning Tree, and Simple Classification and Regression (19, 20). The appropriate algorithm to be used depends on the problem being studied and its constraints, so the algorithm chosen is usually based on literature reports. However, there are no articles describing ML algorithms applied to the problem addressed by the present work. For this reason, an exhaustive test of all listed algorithms was executed. Cross-referencing of 23 clinical and seven epidemiological variables was performed in order to evaluate if a patient case might prove fatal. Cases in which the evolution was recorded as "ignored" do not contribute positively to the ML process because they introduce a component of uncertainty about the evolution of the case, and so, these cases were excluded from the sample space.

Decision trees were built and optimized using cross-validation over a $k$ number of folds. In such $k$-fold cross-validation, the original sample is randomly partitioned into $k$ subsamples. Among all $k$ subsamples, a single one is retained as the validation data for testing the model, and the remaining $k-1$ subsamples are used as training data. The cross validation process is then repeated $k$ times (the folds), with each of the $k$ subsamples used exactly once as the validation data. Then, the $k$ results from the folds are averaged to produce a single estimation. This procedure was accomplished by using the free software Weka (Waikato Environment for Knowledge Analysis) (19).

\section{Mapping Process}

The mapping process was performed using the most relevant attributes of the previously discussed analyses and the confirmed cases of SF. The observations of the confirmed cases were studied by measures of central tendency and distribution according to case evolution: recovered, death, and ignored. At this stage, the cases recorded as confirmed by laboratories were compared with the criteria set out in the epidemiological surveillance guides for the years 2007-2016 $(4,5,21,22)$.

\section{Cartographic Techniques}

Finally, using the data of confirmed SF cases $(n=104)$, a study of patients spatial behavior was undertaken according to residence, infection, and medical care, using the program Terraview (23). Subsequently, this study was exported to the program ArcGis program (24), which was used to develop thematic maps for the identification of spatial patterns.

\section{RESULTS}

Among the 890 SF cases reported in SINAN in RJ, 11.7\% (104) were confirmed as SF; $0.7 \%$ (6) associated with tick bite allergy; $2.9 \%(26)$ as dengue; $1.6 \%$ (14) as leptospirosis, and 10.5\% (93) as other categories. In addition, $72.7 \%$ (647) of reported cases did not have a pathology category provided (Figure 2). 


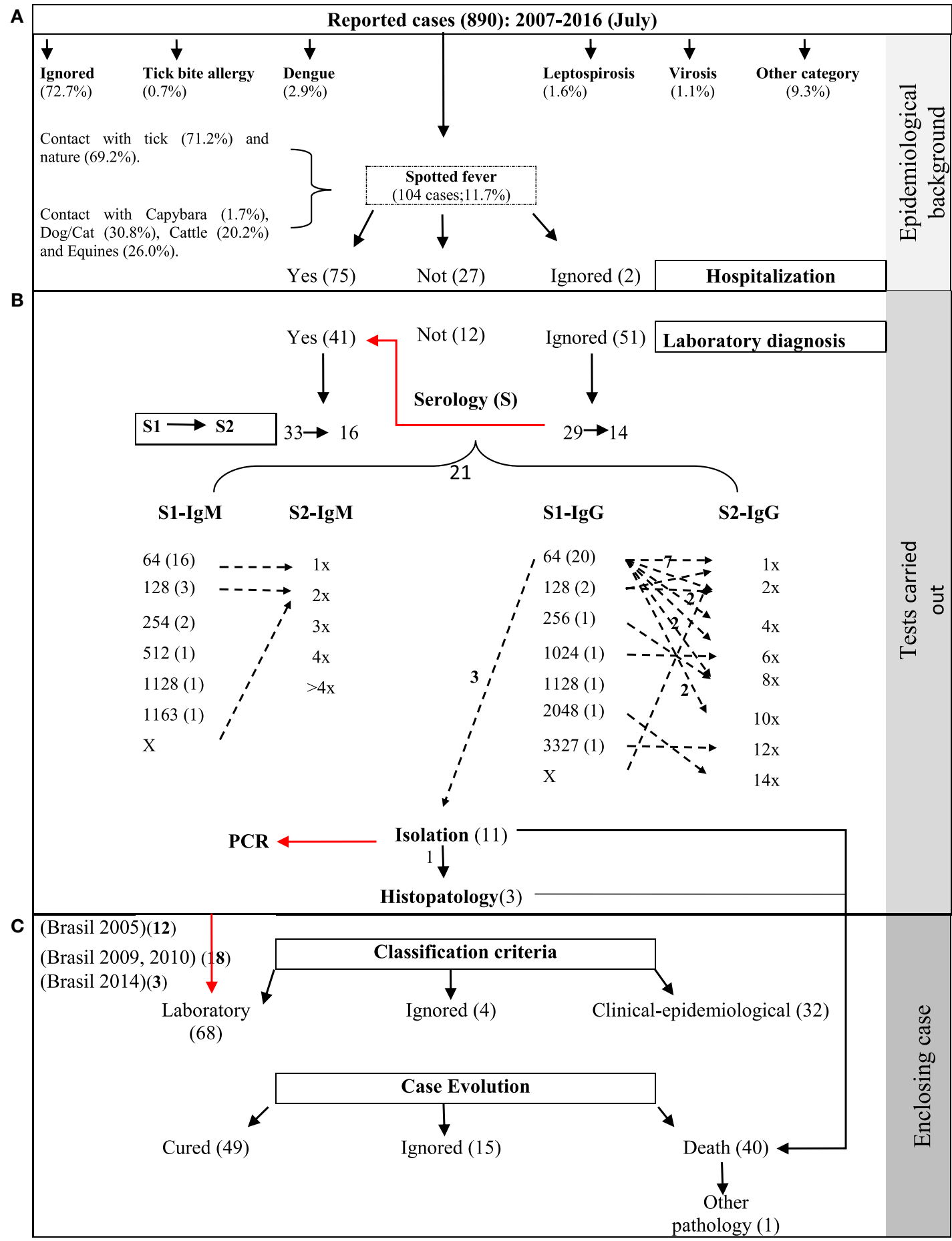

FIGURE 2 | Process map for epidemiological surveillance of spotted fever (SF), 2007-2016. (A) Descriptive epidemiological analysis of the cases reported to SINAN and hospitalization of cases confirmed as SF. Data inconsistency $(\rightarrow)$. For example, of 51 cases without laboratory tests recorded (ignored), evidence was found in 29 using indirect immunofluorescence assay in the first sample and 14 for the paired sample. (B) Follow-up to laboratory techniques and serological titers confirming human cases with SF. Evidence was found for 33 cases through laboratory confirmation following the parameters established for the country $(4,5,21,22)$. Seroconversion serologic titers $(\rightarrow)$, for example, of 20 patients with IgG titers for 1:64 in the first sample (S1), seven exhibited no increase in titers $(1 \times)$, two increased by a factor of four $(4 \times)$, two by a factor of eight $(8 x)$, and two by a factor of 10 (10x). The zeta no number refers to one seroconversion patient. Serologic titers: $1 \times=1: 64,2 \times=1: 128,4 \times=1: 256,6 \times=1: 512,8 \times=1: 1,024,10 \times=1: 2,048,12 \times=1: 4,096,14 \times=1: 8,192$. (C) Comparative evaluation of the serological classification criteria with current technical standards (according to period) of Brazil and final clinical evolution of the patients with SF. 
About 50\% (437) of the reported cases involved hospitalization, but information concerning such hospitalization was available for just 181 patients; that is, there were missing data such as dates of hospitalization and discharge. Among the confirmed SF cases, 75 had been hospitalized, of which, 68 had their diagnosis confirmed by laboratory techniques and 32 by clinical-epidemiologic criteria; the criterion of classification was not recorded for four of the confirmed cases. Regarding the clinical outcome of the cases, $47.1 \%$ (49) of the patients recovered, 38.5\% (40) died, and $14.4 \%$ (15), there was no information report (Figure 2).

Among the clinical signs and symptoms, fever was present in $91.3 \%$ (95) of the confirmed cases, followed by headache, myalgia, prostration, and nausea/vomiting. The proportion of the symptoms remained relatively invariant among cases that turned into death, cases that were cured, and cases that were ignored (Figure 3).

The neural network was able to classify $38.2 \%$ (39/102) of correct instances of diagnosis (Table 1). Observe that the probabilistic bid for choosing the correct diagnosis is $10.0 \%$ since there are 10 possibilities of diseases. Although the $38.2 \%$ hit is higher than such probabilistic bid, it is still a poor classifier for determining the nature and circumstances of a diseased condition. Therefore, the PNN failed to produce good agreement in classifying cases into the pre-established disease categories using clinical and predictive environmental variables. It was observed that the Field 51 from SINAM form for recording the diagnosis was frequently not filled properly, and thus there is a lack of information. Consequently, a reduced sample was used for training the PNN (102 cases), which compromised the performance of the neural network, resulting in a low overall percentage of correct classification.

In the analysis of clinical evolution of patients using data mining and ML, some of the algorithms had irrelevant results; the best results were obtained with the algorithms Best First Decision Tree, J48, and Reduced-Error Pruning Tree. All of the algorithms generated decision trees for identifying probable deaths with only epidemiological variables and no environmental variables.

Using only the 27 clinical variables resulted in Kappa coefficients with higher values and located completely inside the interval of substantial agreement, with the prioritized variables being: respiratory disorders, convulsion, shock, petechiae, coma, icterus, and diarrhea (Table 2).

The machine learning algorithms produced six rules (Table 3) that allow deducing that the evolution of a patient's case will be death.

Of the 104 cases confirmed as SF, 103 were from 25 municipalities of RJ and one from the municipality of Guarulhos, São Paulo-SP. Ninety eight of these confirmed cases were found to be for patients who reside in 15 municipalities of RJ and 1 municipality (Tombos) of Minas Gerais (MG) (Figure 4).

\section{DISCUSSION}

This study was not able to make a diagnostic classification of suspected cases of SF through clinical signs and symptoms using

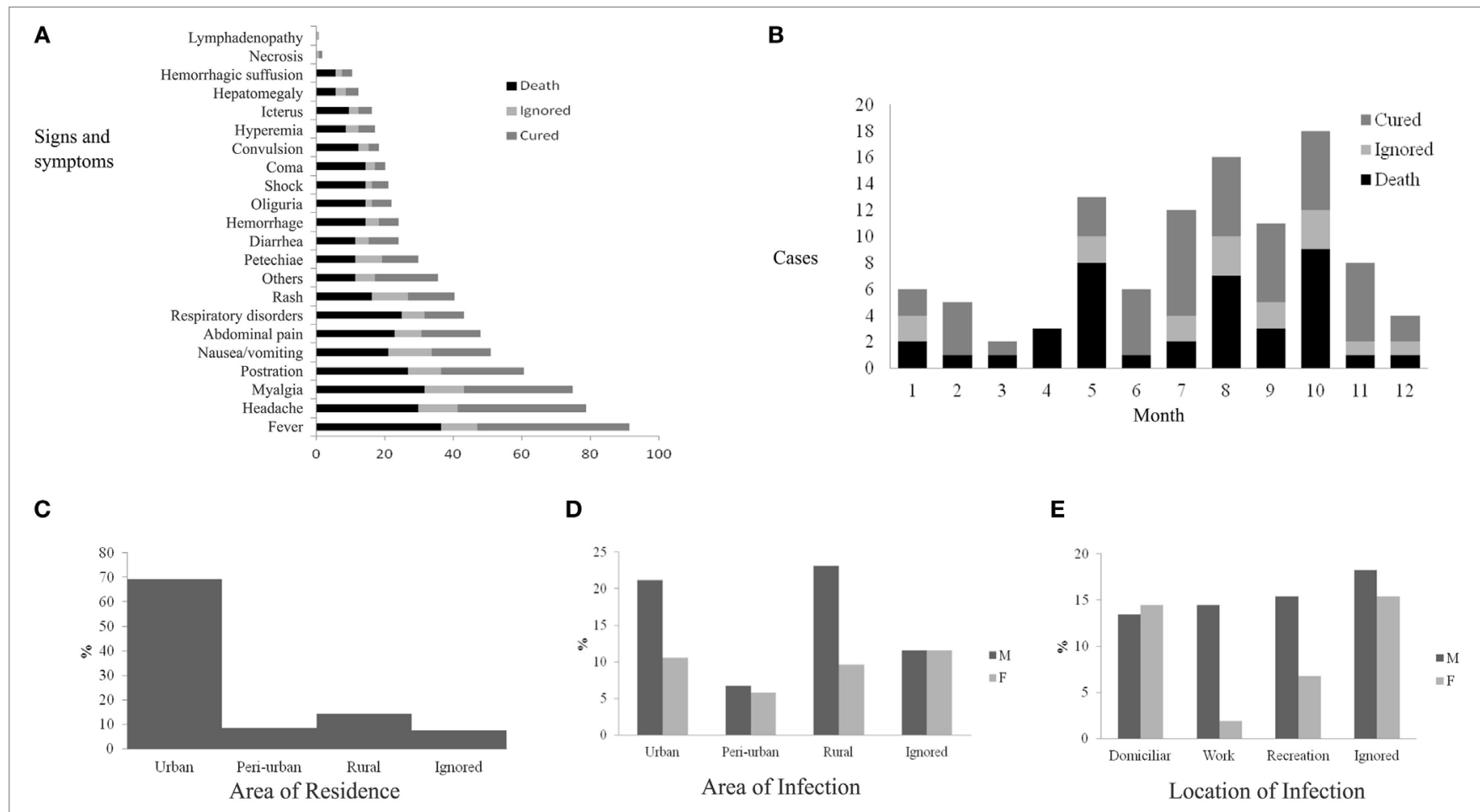

FIGURE 3 | Epidemiological dynamics of spotted fever in the state of Rio de Janeiro, 2007-2016 (July): clinical signs and symptoms (A), monthly distribution according to the progress of cases (B), area of residence (C), area of infection (D), and local infection (E) of patients. 
TABLE 1 | Diagnosis classification using bayesian probabilistic classification neural network in the state of Rio de Janeiro.

\begin{tabular}{lrc}
\hline Diagnosis & Cases & Correct instances \\
\hline Cellulitis & 2 & $0(0.0 \%)$ \\
Dengue & 14 & $4(28.6 \%)$ \\
Encephalitis & 1 & $1(100.0 \%)$ \\
Hapatitis A & 2 & $0(0.0 \%)$ \\
Meningitis & 3 & $0(0.0 \%)$ \\
Leptospirosis & 7 & $2(28.6 \%)$ \\
Other disease & 31 & $11(35.5 \%)$ \\
Spotted fever & 38 & $21(55.3 \%)$ \\
Tick bite allergy & 2 & $0(0.0 \%)$ \\
Virosis & 2 & $0(0.0 \%)$ \\
Total & 102 & $39(38.2 \%)$
\end{tabular}

TABLE 2 | Classification of cases of spotted fever in the state of Rio de Janeiro as death or recovery using epidemiological variables and prioritized clinical variables.

\begin{tabular}{|c|c|c|c|c|}
\hline Algorithm & Kappa & $\begin{array}{c}\text { Correct } \\
\text { instances (\%) }\end{array}$ & Folds & $\begin{array}{l}\text { Selected tree decision } \\
\text { variables }\end{array}$ \\
\hline $\begin{array}{l}\text { Best First } \\
\text { decision tree }\end{array}$ & 0.2935 & 67.1 & 19 & $\begin{array}{l}\text { Contact with tick, cattles, } \\
\text { woods-forest-river- } \\
\text { waterfalls, other }\end{array}$ \\
\hline $\mathrm{J} 48$ & 0.3648 & 70.5 & 22 & $\begin{array}{l}\text { Contact with woods-forest- } \\
\text { river-waterfalls, other }\end{array}$ \\
\hline $\begin{array}{l}\text { Reduced-error } \\
\text { pruning tree }\end{array}$ & 0.3159 & 68.2 & 12 & $\begin{array}{l}\text { Contact with woods-forest- } \\
\text { river-waterfalls, other }\end{array}$ \\
\hline $\begin{array}{l}\text { Best first } \\
\text { decision tree }\end{array}$ & 0.68 & 84.1 & 28 & $\begin{array}{l}\text { Respiratory disorders, } \\
\text { convulsion }\end{array}$ \\
\hline $\mathrm{J} 48$ & 0.62 & 80.9 & 8 & $\begin{array}{l}\text { Respiratory disorders, } \\
\text { convulsion }\end{array}$ \\
\hline $\begin{array}{l}\text { Reduced-error } \\
\text { pruning tree }\end{array}$ & 0.62 & 80.7 & 4 & $\begin{array}{l}\text { Coma, convulsion, icterus, } \\
\text { respiratory disorders, } \\
\text { diarrhea }\end{array}$ \\
\hline
\end{tabular}

TABLE 3 | Prediction rules obtained by machine learning for death from spotted fever (SF) in the state of Rio de Janeiro.

\begin{tabular}{|c|c|c|c|}
\hline \multicolumn{2}{|c|}{ Rule } & \multirow{2}{*}{$\begin{array}{c}\text { Reliability (\%) } \\
63.2\end{array}$} & \multirow{2}{*}{$\begin{array}{c}\text { Support (\%) } \\
61.5\end{array}$} \\
\hline $\mathrm{R} 1$ & Respiratory disorders $\rightarrow$ death & & \\
\hline $\mathrm{R} 2$ & $\begin{array}{l}\neg \text { Respiratory disorders ^ convulsion } \\
\rightarrow \text { death }\end{array}$ & 85.7 & 15.4 \\
\hline R3 & Coma $\rightarrow$ death & 100.0 & 30.8 \\
\hline R4 & $\begin{array}{l}\neg \text { Coma }^{\wedge} \text { icterus }{ }^{\wedge} \text { respiratory } \\
\text { disorders } \rightarrow \text { death }\end{array}$ & 100.0 & 10.3 \\
\hline R5 & $\begin{array}{l}\neg \text { Coma }^{\wedge} \neg \text { icterus ^ convulsion } \\
\rightarrow \text { death }\end{array}$ & 75.0 & 7.7 \\
\hline R6 & $\begin{array}{l}\neg \text { Coma }^{\wedge} \neg \text { icterus }^{\wedge} \neg \text { convulsion }{ }^{\wedge} \\
\neg \text { diarrhea }{ }^{\wedge} \text { respiratory disorders } \rightarrow \\
\text { death }\end{array}$ & 60.0 & 7.7 \\
\hline
\end{tabular}

Note that the possible consequences for patient disease are death or recovery, so the random probability of death is $50 \%$. This means that any rule with confidence value higher than $50 \%$ is better than random choice. For each of these rules, we calculated the values of two metrics: support, which indicates the percentage of SF notification records in the sample space that endorse the rule; reliability, which indicates the percentage of SF notification records whose patients in fact died when presenting the clinical symptoms described in the rule. techniques of neural networks. However, ML for knowledge representation provided good results. Rash and the presence of petechiae seem to be strong indicators of SF (5-7) and were present in $40.4 \%(42 / 104)$ and $29.8 \%(31 / 104)$ of the cases, respectively (Figure 3 ).

Although $71.0 \%(74 / 104)$ of the confirmed SF patients had contact with a tick and $69.2 \%(72 / 104)$ had performed some activity in nature, these were not factors unique to the disease. In fact, laboratory tests confirmed cases for dengue and leptospirosis, $53.3 \%(8 / 15)$ and $62.5 \%(5 / 8)$, respectively, in which subjects had also had contact with ticks. However, contact with ticks as a historical factor of suspected SF remains important $(3,25,26)$, while contact with capybaras, present in $1.7 \%(2 / 104)$ of cases, is not a relevant factor in suspected SF in the state of RJ (27), as established in the surveillance protocols for Brazil $(4,5,21,22)$.

This study found that some changes need to be made to the SF notification report form (28). The "ignored" alternative, which appears in various fields/variables such as sex, area of residence, all clinical signs, and symptoms, among others, makes it difficult or even impossible to achieve a deeper understanding of the epidemiological dynamics of SF and evaluate the sensitivity of SINAN, as was the case in this study. Thus, we recommend binary responses for such fields (1 or 2).

Moreover, the separation of dogs and cats in Field 34, regarding Epidemiology group, seems to be important (28), since dogs have been shown to be an important amplifier for $R$. rickettsii, Brazil $(29,30)$, and they usually act as hosts for several species of ticks in endemic areas of SF (31-33).

Furthermore, we emphasize the importance of instructing qualified SS professionals on how to correctly complete the epidemiological investigation forms from SINAN. We noticed, for example, that the field responsible for recording the diagnosis (Field 51) was frequently filled improperly, which caused a $72.7 \%$ $(647 / 870)$ drop in the original sample size of cases. In fact, this lack of information compromised the performance of the neural networks, resulting in a low overall percentage of correct classification (45.6 and 37.3\%; results not shown).

It is very important to mention that based on laboratory classification criteria $(4,5,21,22)$, only $48.5 \%(33 / 68)$ of the cases were confirmed by indirect immunofluorescence assay (IFA), isolation, and histopathology; the remaining cases did not meet criteria for laboratory classification (see in detail in Figure 2). Moliterno (34) previously made this same observation for confirmed cases in RJ from 2004 to 2008.

According to the technical staff of SES-RJ (personal communication), there was a critical situation at SINAN regarding this issue; that is, cases appearing confirmed by isolation mostly corresponded to results of PCR techniques, because there was no option on the epidemiological form for PCR (28), and so the isolation option was selected instead.

As expected, the decision trees analysis reinforced the hypothesis that epidemiological variables are not predisposing factors for the clinical evolution of the patient, as some clinical signs and symptoms are (Table 2). These results suggest that two experts on SF would agree with each other with a high frequency in their prediction of the clinical evolution (death or recovery) of cases 


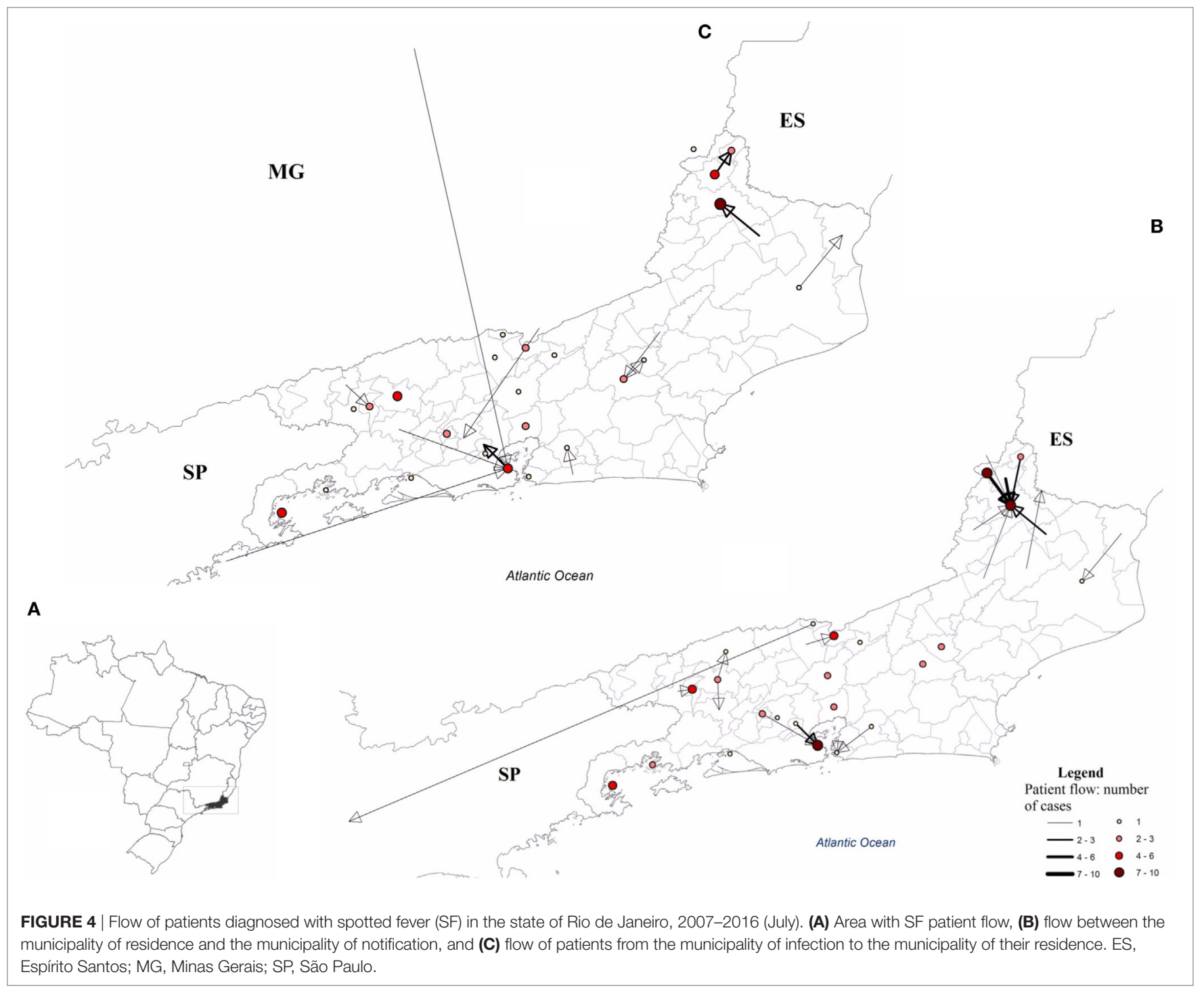

using the same clinical variables: respiratory disorders, convulsion, shock, petechiae, coma, icterus, and diarrhea. Some of these symptoms have also been associated with more severe clinical evolution and higher case-fatality by $\operatorname{SF}(3,7,25,26)$.

In trying to prioritize symptoms, $\mathrm{ML}$ algorithms produced six rules (Table 3 ) that allow deducing that the evolution of a particular case will be death. Recall that any rule with a confidence value higher than $50 \%$ is better than a random choice, and thus increases the probability of predicting death. Rule R4, for example, is associated with $10.3 \%$ of the sample space with $100.0 \%$ confidence; in other words, the patient will die if he has coma or convulsion and also if he has respiratory disorders with or without icterus. This analysis produced intermediate Kappa coefficient values, located at the border between the classes seen as in moderate agreement and substantial agreement (35).

There is a dynamic flow of patients among RJ municipalities and bordering states (Espírito Santo, Minas Gerais, and São Paulo), which requires future work to integrate a more detailed spatial component of the sites of infection for a greater understanding of the epidemiological dynamics of SF.

Overall, the findings here are of the utmost importance to SINAN and the SS for SF. They indicate that changes to the epidemiological form for SF are needed, that qualification of SS personnel should be improved, and that pilot studies should be established on sensitivity, focused in areas with a greater number of cases as well as epidemiological silent areas of the state of RJ.

Given the low quality of the SF case data in SINAN for the state of RJ, the artificial neural networks were not able to generate robust predictive projections. Therefore, we recommend the selection of a set of municipalities with greater epidemiological burdens of SF in RJ for future prospective study applying these techniques.

Since some diagnostic categories are very rare, for example, encephalitis, and occur only a few times in the data set, it would be advisable to limit the exit space of the PNN to more frequent and related groups of pathologies, or to do so alone with SF and other pathologies. Comparative studies with other statistical tests 
are needed, such as with Linear and Quadratic Discriminant Analysis.

\section{AUTHOR CONTRIBUTIONS}

DL-contributed to the concept and design; DL and FM-contributed to the design and application of $\mathrm{M}-\mathrm{L}$ techniques and DL and CD with cartographic techniques; CD, PA, and MA with acquisition of the epidemiological information; FM, GG, and $\mathrm{RB}-$ contributed to concept and design of the research project, data acquisition, and interpretation of results. All authors contributed to critically revising the manuscript for important intellectual content and final approval of the version to be published. All authors are in agreement to be accountable for all aspects of the work and in ensuring that questions related to the accuracy or integrity of any part of the work have been appropriately investigated and resolved.

\section{REFERENCES}

1. Angerami RN, Resende MR, Feltrin AF, Katz G, Nascimento EM, Stucchi RS, et al. Brazilian spotted fever: a case series from an endemic area in Southeastern Brazil: clinical aspects. Ann N Y Acad Sci (2006) 1078:252-4. doi:10.1196/ annals.1374.044

2. deOliveiraS, Guimarães JN, ReckziegelGC, Neves BM, da C, Araújo-Vilges KM, et al. An update on the epidemiological situation of spotted fever in Brazil. J Venom Anim Toxins Incl Trop Dis (2016) 22:22. doi:10.1186/s40409016-0077-4

3. de Lemos ER, Alvarenga FB, Cintra ML, Ramos MC, Paddock CD, et al. Spotted fever in Brazil: a seroepidemiological study and description of clinical cases in an endemic area in the state of Sao Paulo. Am J Trop Med Hyg (2001) 65:329-34. doi:10.4269/ajtmh.2001.65.329

4. Brasil. Febre Maculosa Brasileira. In: Penna G, Teixeira M, Costa M, Pereira S, Carmo E, do Nascimento E, editors. Guia de Vigilância Epidemiológica. Brasilia DF: Ministério da Saúde/Secretaria de VigilânciaemSaúde/ Departamento de VigilânciaEpidemiológica (2009). p. 1-14. Available from: http://bvsms.saude.gov.br/bvs/publicacoes/guia_vigilancia_epidemiologica_7ed.pdf

5. Brasil. Febre Maculosa Brasileira e Outras Riquetsioses. In: da Silva J, editor. Guia de VigilânciaemSaúde. Brasilia DF: Secretaria de VigilânciaemSaúde/ Ministerio da Saúde (2014). p. 445-54. Available from: http://portalsaude. saude.gov.br/images/pdf/2014/novembro/27/guia-vigilancia-saudelinkado-27-11-14.pdf

6. Monteiro KJL, Rozental T, Lemos ERS. Diagnóstico diferencial entre a Febre Maculosa Brasileira e o Dengue no contexto das doençasfebrisagudas. Rev Patol Trop (2014) 43:241-50. doi:10.5216/rpt.v43i3.32220

7. Pinter A, França A, de Souza C, Sabbo C, do Nascimento E, dos Santos F, et al. Febre Maculosa Brasileira. Sao Paulo: Centro de produção e divulgaçãocientífica CCD/SES-SP (2011).

8. Klaucke DN, Buehler MDJW, Thacker MDSB, Parrish MDRG, Trowbridge MDFL, Berkelman MDRL, et al. Guidelines for evaluating surveillance systems. MMWR Morb Mortal Wkly Rep (1988) 37:1-12.

9. IBGE. Demografia do estado do Rio de Janeiro. (2016). Available from: http:// www.ibge.gov.br/estadosat/perfil.php?sigla $=$ rj

10. Brasil. Resolução 466/12 do Conselho Nacional de Saúde/MS SobreDiretrizes e NormasRegulamentadoras de Pesquisaenvolvendosereshumanos. (2012). Available at: http://bvsms.saude.gov.br/bvs/saudelegis/cns/2013/res0466_12_ 12_2012.html

11. Specht DF. Probabilistic neural networks. Neural Netw (1990) 3:109-18. doi:10.1016/0893-6080(90)90049-Q

12. Pitarque A, Roy JF, Ruiz JC. Redesneurales vs modelosestadísticos: simulaciones sobre tareas de predicción y clasificación. Psicológica (1998) 19:387-400.

\section{ACKNOWLEDGMENTS}

The authors thank the Secretarias Municipais e Estaduais de Saúde (Secretary Municipal and of State of Health) of RJ for logistic and administrative support in acquiring information. Special thanks go to the MS evaluators who made excellent contributions to its improvement. We thank Dr. Erik Russell Wild, American biologist from University of Wisconsin, for providing a native English speaker revision of the manuscript.

\section{FUNDING}

The article is part of the doctoral thesis of DL and was supported by the Ph.D. scholarship program funded by Coordenação de Aperfeiçoamento de Pessoal de Nível Superior (Capes-BrasilsemMiséria)/FIOCRUZ.

13. Statpoint Technologies I. Clasificador de Redes Neurales. Statgraphics. Madrid: StatPoint, Inc. (2006). p. 1-17.

14. Wu SGG, Bao FSS, Xu EYY, Wang Y-X, Chang Y-F, Xiang Q-L. A leaf recognition algorithm for plant classification using probabilistic neural network. Int Symp Signal Process Inf Technol (2007) 1:1-6. doi:10.1109/ISSPIT.2007.4458016

15. El Emary IMM, Ramakrishnan S. On the application of various probabilistic neural networks in solving different pattern classification problems. World Appl Sci J (2008) 4:772-80.

16. Statpoint Technologies I. STATGRAPHICS ${ }^{\circledR}$ Centurion. (2006). Available from: http://www.statgraphics.com/

17. de Mello FL, de Carvalho RL. Knowledge geometry. J Inf Knowl Manag (2015) 14:1550028. doi:10.1142/S0219649215500288

18. Stuart R, Norvig P. Learning from observations. In: Stuart R, Norvig P, editors. Artificial Intelligence: A Modern Approach. New Jersey: Pearson Education, Inc. (2003). p. 649-76

19. Hall M, Frank E, Holmes G, Pfahringer B, Reutemann P, Witten IH. The WEKA data mining software. ACM SIGKDD Explor Newsl (2009) 11:10-8. doi:10.1145/1656274.1656278

20. Rokach L, Maimon O. Classification trees. In: Maimon O, Rokach L, editors. Data Mining and Knowledge Discovery Handbook. Secaucus, NJ: SpringerVerlag New York, Inc (2005). p. 149-74.

21. Brasil. Guia de Vigilãncia Epidemiológica. 5th ed. Brasilia, DF: (2005). Available from: http://bvsms.saude.gov.br/bvs/publicacoes/Guia_Vig_Epid_ novo2.pdf

22. Brasil. Doenc, asinfecciosas e parasitarias: Guia de bolso. 7a ed. Brasilia: (2010). Available from: http://bvsms.saude.gov.br/bvs/publicacoes/doencas_infecciosas_guia_bolso_7ed_2008.pdf

23. INPE. TerraView. Brazilian National Institute for Space Research, São José dos Campos: DPI (2010). Available from: http://www.dpi.inpe.br/terralib5/ wiki/doku.php

24. Esri. ArcGIS for Desktop. Esri (2016). 1 p. Available from: http://www.esri. com/software/arcgis/arcgis-for-desktop

25. Angerami RN, Resende MR, Feltrin AF, Katz G, Nascimento EM, Stucchi RS, et al. Brazilian spotted fever: a case series from an endemic area in Southeastern Brazil: epidemiological aspects. Ann N Y Acad Sci (2006) 1078:170-2. doi:10.1196/annals.1374.030

26. de Lemos E, Rozental T, Villela CL. Brazilian spotted fever: description of a fatal clinical case in the State of Rio de Janeiro Febremaculosabrasileira: descrição de um caso fatal no Estado do Rio de Janeiro. Rev Soc Bras Med Trop (2002) 35:523-5. doi:10.1590/S0037-86822002000500017

27. Montenegro DC, Bitencourth K, de Oliveira SV, Borsoi AP, Cardoso KM, Sousa MSB, et al. Spotted fever: epidemiology and vector-rickettsia-host relationship in Rio de Janeiro state. Front Microbiol (2017) 8:505. doi:10.3389/ fmicb.2017.00505 
28. MS. Ficha de investigação-febreMaculosa/Rickettsioses. (2006). p. 41-2. Available from: http://www.ebserh.gov.br/documents/222346/1207905/ FEBRE+MACULOSA.pdf/31a5e998-4e09-4842-95a0-dd3da5470dd0

29. Piranda, Eliane M, Faccini JL, Pinter A, Pacheco RC, Cancãdo PH, et al. Experimental infection of Rhipicephaluss anguineus ticks with the bacterium Rickettsia rickettsii, using experimentally infected dogs. Vector Borne Zoonotic Dis (2011) 11:29-36. doi:10.1089/vbz.2009.0250

30. Piranda EM, Faccini JLH, Pinter A, Saito TB, Pacheco RC, Hagiwara MK, et al. Experimental infection of dogs with a Brazilian strain of Rickettsia rickettsii: clinical and laboratory findings. Mem Inst Oswaldo Cruz (2008) 103:696-701. doi:10.1590/S0074-02762008000700012

31. Cunha N, Fonseca A, Rezende J, Rozental T, Favacho A, Barreira J, et al. First identification of natural infection of Rickettsia rickettsii in the Rhipicephalus sanguineus tick, in the State of Rio de Janeiro. Pesqui Veterinária Bras (2009) 29:105-8. doi:10.1590/S0100-736X2009000200003

32. Gehrke FS, Gazeta GS, Souza ER, Ribeiro A, Marrelli MT, Schumaker TTS. Rickettsia rickettsii, Rickettsia felis and Rickettsia sp. TwKM03 infecting Rhipicephalus sanguineus and Ctenocephalides felis collected from dogs in a Brazilian spotted fever focus in the State of Rio De Janeiro/Brazil. Clin Microbiol Infect (2009) 15:267-8. doi:10.1111/j.1469-0691.2008. 02229.x

33. Ogrzewalska M, Saraiva DG, Moraes-Filho J, Martins TF, Costa FB, Pinter A, et al. Epidemiology of Brazilian spotted fever in the Atlantic Forest, state of São Paulo, Brazil. Parasitology (2012) 139:1283-300. doi:10.1017/ S0031182012000546

34. Moliterno FM. Febre maculosa brasileira : aspectos epidemiológicos clínicos e laboratorias dos casos ocorridos no estado do Rio de Janeiro no período de janeiro de 2004 a dezembro de 2008. (2009). Available from: http://www.arca. fiocruz.br/xmlui/handle/icict/3831

35. Viera A, Garrett J. Understanding Interobserver Agreement Using the Kappa Statistic. (2005). Available from: http://wwwl.cs.columbia.edu/ julia/courses/ CS6998/Interrater_agreement.Kappa_statistic.pdf

Conflict of Interest Statement: The authors declare that they have prepared the manuscript in accordance with the standards of the journal, have the exclusive responsibility for the accuracy and correctness of the contents of the article submitted, and declare that they have no conflicts of interest.

Copyright (C) 2017 Lopez, de Mello, Giordano Dias, Almeida, Araújo, Magalhães, Gazeta and Brasil. This is an open-access article distributed under the terms of the Creative Commons Attribution License (CC BY). The use, distribution or reproduction in other forums is permitted, provided the original author(s) or licensor are credited and that the original publication in this journal is cited, in accordance with accepted academic practice. No use, distribution or reproduction is permitted which does not comply with these terms. 